\title{
Günlük Hasta Sayısı ile Google Topluluk Hareket Raporları Arasındaki İlişkilerin Negatif Binom Regresyonla İncelenmesi: Covid-19 Türkiye Örneği
}

\author{
Serkan AKOGUL ${ }^{* 1}$, Enes FILIIZ ${ }^{2}$ \\ ${ }^{1}$ Pamukkale Üniversitesi, Fen Edebiyat Fakültesi, İstatistik Bölümü, 20000, Denizli, Türkiye \\ ${ }^{2}$ Fırat Üniversitesi, Fen Fakültesi, İstatistik Bölümü, 23000, Elâzığ, Türkiye
}

(Alınış / Received: 02.06.2021, Kabul / Accepted: 16.08.2021, Online Yayınlanma / Published Online: 25.12.2021)

Anahtar Kelimeler

Covid-19,

Günlük hasta sayısı, Google topluluk hareket raporları,

Negatif binom regresyon analizi.
Özet: Dünyayı etkisi altına alan yeni tip koronavirüs (Covid-19) salgınından dolayı sosyal mesafe ve hareketliliğin azaltılması en önemli tedbirler olarak uygulanmaktadır. Dünya genelinde daha az hareketliliğin daha düșük Covid-19 vaka ve hasta sayıları ile ilişkili olduğunu göstermektedir. Özellikle ülkemizde Covid-19 vaka ve hasta sayılarında; kısmen ya da tam kapanmalar ile düşüş, kademeli ya da tam normalleşme adımları ile de artış gözlemlenmiştir. Bu çalışmada, Türkiye Covid-19 günlük hasta sayısı ile Türkiye Google topluluk hareket raporları arasındaki ilişkinin ortaya konulması amaçlanmıştır. Betimleyici ve ilişski arayıcı türde gerçekleştirilmiș olan araştırma da Türkiye'de ilk Covid-19 hastasının görüldüğü 11 Mart 2020 ile 11 Mart 2021 tarihleri arasındaki bir yıllık verilerden yararlanılmıştır. Araştırmadan elde edilen verilerin değerlendirilmesinde, betimsel istatistikler ve negatif binom regresyon analizi kullanılmıştır. Analiz sonuçlarına göre insan hareketliliğin artması hasta sayısının artmasına neden olduğu gibi konutlardaki hareketliliğinde yine hasta sayısına pozitif etki yaptığı bulunmuştur.

\section{Examining the Relationships between Number of Daily Patients and Google Community Mobility Reports with Negative Binomial Regression: The Case of Covid-19 Turkey}

\section{Keywords}

Covid-19,

Number of daily patient, Google Community Mobility Reports,

Negative binomial regression analysis.

\begin{abstract}
Due to the new type of coronavirus (Covid-19) epidemic that affects the world, social distance and reducing mobility are implemented as the most important measures. It shows that less mobility is associated with lower Covid-19 cases and patient numbers worldwide. Especially in the number of Covid-19 cases or patients in our country; A decrease was observed with partial or full closures, and an increase was observed with gradual or full normalization steps. In this study, it is aimed to reveal the relationship between Turkey Covid-19 the number of daily patients and Turkey Google community mobility types. Descriptive and relationship-seeking research was conducted using one-year data between March 11, 2020 and March 11, 2021, when the first Covid-19 patient was seen in Turkey. Descriptive statistics and negative binomial regression analysis were used to evaluate the data obtained from the study. According to the results of the analysis, it was found that the increase in human mobility caused an increase in the number of patients, as well as a positive effect on the number of patients in the mobility in the residences.
\end{abstract}

\section{Giriş}

Covid-19, Aralık 2019'un ortasından ilk defa Çin'de görülen ve dünyaya hızla yayılan bir salgın olarak tanımlanmıştır [1]. Türkiye'de ise ilk Covid-19 vakası 11 Mart 2020'de görüldü ve şu anda salgının neden olduğu çok sayıda hasta ve ölüm sayıları kaydedilmektedir [2]. Ayrıca Türkiye, salgını kontrol altında tutmak ve halk sağlığını korumak için hareketliliğin azaltılması yönünde bazı önlemler uygulamaktadır. Bu nedenle Google topluluk hareket türlerinin, Türkiye'de Covid-19'un yayılması üzerindeki etkisinin incelenmesi faydalı olacaktır. Hareketliliğin hasta sayısı ile doğrudan bağlantılı olduğu düşüncesinden yola çıkılarak; Türkiye'deki Covid-19 hasta sayısı ile hareketlilik türleri arasındaki regresyon modelinin analiz edilmesi düşünülmüştür. 
Regresyon analizinde farklı veri setleri için farklı regresyon modelleri kullanılabilmektedir. Arzu ve Önder (2013), çalışmalarında farklı veri setleri için kullanımı uygun regresyon yöntemlerini derlemişlerdir [3]. Literatürde sayma veri setleri için poisson ve negatif binom regresyon yöntemleri kullanılmış ve karşılaştırmalar yapılmıștır [4-6]. Kibar (2015) çalışmasında, poisson, negatif binom ve sıfır değer ağırlıklı negatif binom regresyon modellerini kullanmış ve model parametresi tahmininde negatif binom regresyonun iyi sonuç verdiğini belirlenmiştir [7].

Literatürde, güncel olarak Covid-19 virüsünden dolayı topluluk hareket raporlarının sıklıkla incelendiği belirlenmiştir. Saha vd. (2020), Hindistan'ın farklı eyaletleri için mekânsal zaman serisi değişiminin Covid-19 için Google topluluk hareketliliği üzerindeki etkisini incelemişlerdir [8]. Sulyok ve Walker (2020), Covid-19 ile topluluk hareketliliği arasında ilişki olup olmadığını incelemek için çapraz korelasyonlardan ve bayes bilgi kriterlerinden yararlanmışlardır [9]. Wang ve Yamamoto (2020), Amerika'nın Arizona eyaletinde, Google topluluk hareket türleri ile Covid-19 vakaları için bir tahmin modeli sağlamayı amaçlamışlardır [10]. Vokó ve Pitter (2020), Covid-19 salgınının akışındaki değişimin 28 Avrupa ülkesinin sosyal mesafe endeksi ile ilişkisi Google topluluk hareket türleri ile incelenmiştir [11]. Huynh (2020), Covid-19 Google topluluk hareket türlerinden yaralanarak sosyal mesafenin uygulanmasında kültürel boyutun rolünü incelemeyi amaçlamıştır [12]. Savaris vd. (2021) çalışmalarında, matematiksel bir model ile evde kalmanın Covid-19 bulaşmasını azaltmada baskın bir rol oynamadığını ortaya koymuştur [13]. Yilmazkuday (2021), çalışmasında Google topluluk hareket türlerinden yararlanmış ve günlük vaka ve ölümler ile ilişkili olduğunu ortaya koymuştur [14]. Kartal vd. (2021) çalışmalarında, gelişmekte olan bir ülke örneği için Türkiye'ye odaklanarak hareketlilik ile COVID-19 salgını arasındaki ilişkiyi incelemişlerdir [15].

Bu çalışmada Türkiye Google topluluk hareket türleri ile Türkiye Covid-19 günlük hasta sayısı arasındaki ilişkilerin negatif binom regresyon ile incelenmesi amaçlanmıştır. Bu amaç doğrultusunda Türkiye'de Covid-19 vakasının ilk görüldügü günden itibaren (11 Mart 2020) bir yıllık zaman diliminde Türkiye Google topluluk hareket türleri ile ilişkilendirme yapılacaktır.

\section{Materyal ve Metot}

\subsection{Veri seti}

Türkiye Covid-19 günlük hasta sayılarının incelenmesi için Google topluluk hareket türlerinden yararlanılacaktır. Google tarafından açıllanan topluluk hareketlilik türleri "perakende ve rekreasyon" (Restoran, eğlence parkı, kafe, alışveriş merkezi, sinema vb.), "market ve eczane" (Market, pazar, gıda deposu, özel ürünlerin satıldığı gıda dükkânı ve eczane vb.), "parklar" (Milli parklar, halka açık parklar, yat limanları, köpek parkları, halk plajları, plazalar vb.), "toplu taşıma istasyonları" (otobüs, metro ve tren istasyonları vb.), "iş yerleri" ve "konutlar" olarak altı kategoriye ayrılmıştır. Bunlar belirlenen başlıklar altında insanların hareket trendini göstermektedir. Günlük olarak açıklanan veriler referans değerine göre değerlendirilmektedir. Referans değeri, 3 Ocak-6 Şubat 2020 tarihleri arasındaki 5 haftalı döneme ait ortanca olarak belirlenmektedir [16]. Bu değişkenlerin yanı sıra T.C. Sağlık Bakanlığı tarafından açıklanan günlük hasta sayıları kullanılmıştır [2]. Ayrıca çalışmada Türkiye'de ilk hastanın görüldügü 11 Mart 2020 ile 11 Mart 2021 tarihleri arasindaki bir yllık verilerden yararlanılmıştır.

Literatür incelendiğinde Covid-19 virüsün kuluçka (inkübasyon) süresi 2 ila 14 gün arasında olup ortalama sürenin 5 gün olduğu ortaya konmuştur $[2,17,18]$. Bu nedenle çalışmada ilk hastanın görüldüğü 11 Mart 2020 hasta sayısına karşılık olarak 5 gün önceki 6 Mart 2020 Google topluluk hareket türleri verileri ilişkilendirilmiş olup diğer tarihlerde benzer şekilde ayarlanmıștır. Çalışmada kullanılacak olan bağımlı ve bağımsız değişkenlere ait 1 yıllık değişim grafiği Şekil 1 ve Şekil 2 de verilmiștir.

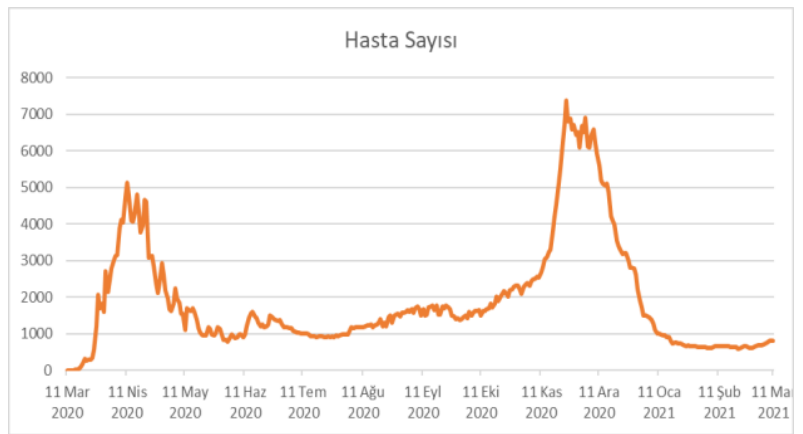

Șekil 1. 11 Mart 2020-11 Mart 2021 tarihleri arasında günlük hasta sayısı değişkenindeki günlük değişim

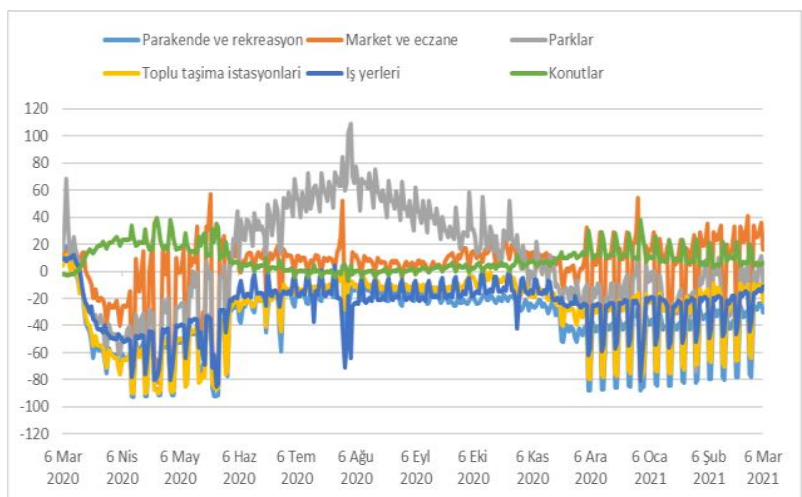

Şekil 2. 6 Mart 2020-6 Mart 2021 tarihleri arasında Türkiye Google topluluk hareket değişkenlerindeki günlük değişim

Türkiye'de ilk koronavirüs vakası 11 Mart 2020'de görülmüştür. Hasta sayısı 2020'nin Nisan ayına kadar artmış olup, uygulanan tedbirlerin etkisiyle rakamlarda ciddi düşüşler olmuştur. Belirli bir süre rakamlar yatay bir eğilim göstermiş olup uygulanan 
kademeli normalleşme adımları ile hasta sayılarında artış olmuştur. İkinci bir pik dediğimiz Kasım 2020'de tekrardan kısıtlamalara gidilmiş olup hasta sayılarında önemli düşüşler gözlemlenmiştir.

Şekil 2'de görüldüğü üzere Google topluluk hareket türleri, zaman içinde artan ve azalan eğilimlere sahiptir. Ayrıca vatandaşların hareketliliğini etkileyen tedbirler doğrultusunda hareketlilik zaman içerisinde değişkenlik göstermiştir. Genel olarak tedbirlerin başında hareketliliğin azaltılması düşüncesi olduğu için Türkiye Google topluluk hareket türleri günlük hasta sayısı üzerinde etkisinin incelenmesi dikkat edilmesi gereken bir husustur. Şekil 3'de Covid-19 hasta sayısı ile Google topluluk hareket türleri arasındaki saçlım grafiği verilmiştir.
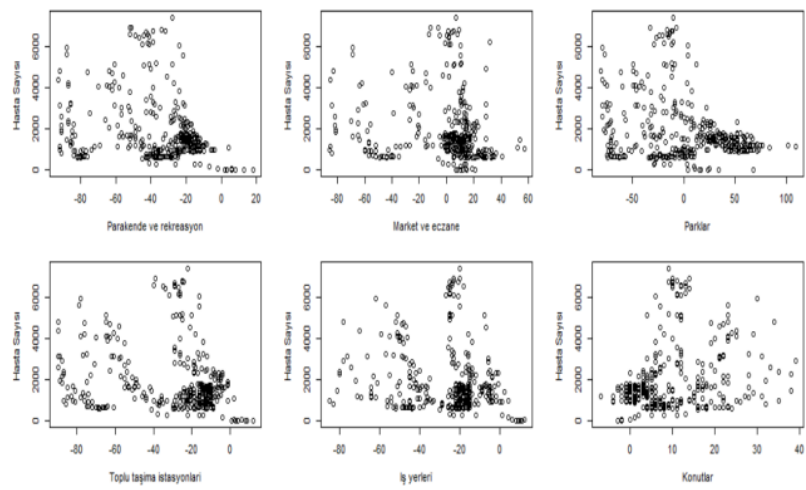

Şekil 3. Covid-19 hasta sayısı ile Google topluluk hareket türleri arasındaki saçlım grafiği

\subsection{Negatif binom regresyon analizi}

Sayma verisinin bir türü, bir olayın belirli bir zaman aralığında kaç kez gerçekleştiğini gösteren negatif olmayan kesikli değerler alan verilerdir. Sayma verisindeki bağımlı değişkene ait varyansın ortalamaya eşit olduğu durumlarda Poisson regresyon modeli, büyük olduğu durumlarda ise negatif binom regresyon modeli önerilmiştir [3-5]. Eğer varyans ortalamaya eşit ise eşit yayılım, büyük ise aşırı yayılım, küçük ise eksik yayılım olarak adlandırılır [19-21]. Negatif binom regresyon modelindeki katsayıların tahmini için slklıkla en çok olabilirlik tahmini kullanılmaktadır [5].

Negatif binom modeli Poisson-Gama karışımı bir dağılıma dayanmaktadır. Negatif binom dağılımının en yaygın kullanımı $\mu$ ortalamalı $\mu+\alpha \mu^{2}$ varyanslı NB2 modeldir. $\alpha \geq 0$ ve $y=0,1$ olmak üzere modelin yoğunluk fonksiyonu;

$$
\begin{aligned}
& f(y \mid \mu, \alpha) \\
& =\frac{\Gamma\left(y+\alpha^{-1}\right)}{\Gamma\left(\alpha^{-1}\right) \Gamma(y+1)}\left(\frac{\alpha^{-1}}{\alpha^{-1}+\mu}\right)^{\alpha^{-1}}\left(\frac{\mu}{\alpha^{-1}+\mu}\right)^{y}
\end{aligned}
$$

şeklindedir. Burada $\Gamma$, gamma fonksiyonu olup $\alpha$ da yayılım parametresidir. $\mu_{i}=\mathrm{e}^{x_{i}^{\prime} \beta}$ üstel ortalama için log olabilirlik fonksiyonu

$$
\begin{aligned}
\ln L(\alpha \beta) & =\sum_{i=1}^{n}\left\{\left(\sum_{j=0}^{y_{i}-1} \ln \left(j+\alpha^{-1}\right)\right)\right. \\
& -\ln y_{i} !-\left(y_{i}+\alpha^{-1}\right) \ln \left(1+\alpha \mathrm{e}^{x_{i}^{\prime} \beta}\right) \\
& \left.+y_{i} \ln \alpha+y_{i} x_{i}^{\prime} \beta\right\}
\end{aligned}
$$

şeklinde olup NB2 modelinde $\alpha$ ve $\beta$ parametrelerin en çok olabilirlik tahmini log olabilirlik fonksiyonunun parametrelere göre türevi sıfıra eşitlenerek bulunur [5-7].

Negatif binom regresyon modellerinin uyum iyiliğinin sınanmasında sapma istatistiği, Pearson istatistiği, olabilirlik oran testi ve Akaike Bilgi kriterleri yaygın olarak kullanılan ölçütler olup kısaca aşağıdaki şekilde yorumlanır:

- Sapma (Değer/sd) nın 1'e eşit olması eşit yayılımı gösterirken 1'den büyük olması aşırı yayılımı ve 1'in altında olması eksik yayılımı gösterir.

- Pearson Ki-Kare (Değer/sd) değeri verilerin modele uyumunu gösteren bir uyum iyiliği ölçütüdür. Bu değer 0.05 'ten küçük ise, model verilere tam olarak uymaz, eğer 0.05 'den büyük ise, model verilere iyi uyuyordur şeklinde yorumlanir.

- Olabilirlik oran testi, modelin boș model ile karşılaştırılmasını sağlayan testtir. Eğer testin p değeri 0.05 'ten küçük ise modelin istatistiksel olarak anlamlı olduğu söylenebilir.

- $\quad$ Akaike Bilgi kriterlerinin en küçük olduğu model, mevcut modeller arasında en uygun model olarak seçilir.

İstatistiksel değerlendirme, bilgisayar ortamında IBM SPSS Statistics 25 yazılımı kullanılarak yapılmıştır. Analizler için anlamlılı seviyesi $\alpha=0.05$ kabul edilmiştir.

\section{Bulgular}

Çalışmada Türkiye Covid-19 günlük hasta sayıları ile Google topluluk hareket türleri arasındaki ilişkinin incelenmesi hedeflenmiştir. $\mathrm{Bu}$ amaç doğrultusunda 11 Mart 2020 ile 11 Mart 2021 tarihleri arasındaki bir yıllık veri seti kullanılarak bağımlı değişken (Günlük hasta sayısı) ile bağımsız değişkenler (Google topluluk hareket türleri) arasındaki regresyon modeli incelenmiştir.

Bağımlı değişken sayma sayılarından oluşmakta olup veri setinde aşırı yayılım tespit edildiği için veri seti negatif binom regresyon modeli ile modellenecektir. Öncelikle regresyon modeli uyum iyiliği ölçütleri tarafından test edilecek, daha sonrada parametre tahminlerinde bulunulacaktır. Böylece bağımlı değişken ile bağımsız değişken arasındaki regresyon modeli ortaya konmuş olacaktır. 
Çalışmada Türkiye Covid-19 günlük hasta sayısı ile Google topluluk hareketlilik türleri arasındaki ilişki negatif binom regresyon ile incelenmiștir. Bağımlı değișken olarak T.C. Sağlık Bakanlığı tarafından açılanan Covid-19 günlük hasta sayıları kullanılmıştır. Bağımsız değişkenler olarak Google topluluk hareketlilik türleri "perakende ve rekreasyon", "market ve eczane", "parklar", "toplu taşıma istasyonları", "iş yerleri" ve "konutlar" alınmıştır. Bağımlı ve bağımsız değişkenlere ait tanımlayıcı istatistikler Tablo 1 de verilmiștir.

Tablo 1. Veri setine ait tanımlayıcı istatistikler.

\begin{tabular}{ccccc}
\hline & Min. & Maks. & Ort. & Std. Sapma \\
\hline Hasta Sayısı & 0 & 7381 & 1913.96 & 1540.23 \\
\hline $\begin{array}{c}\text { Perakende } \\
\text { ve rekreasyon }\end{array}$ & -93 & 18 & -36.64 & 23.99 \\
\hline $\begin{array}{c}\text { Market ve } \\
\text { eczane }\end{array}$ & -86 & 57 & -0.74 & 27.48 \\
\hline Parklar & -81 & 109 & 1.97 & 42.48 \\
\hline $\begin{array}{c}\text { Toplu taşıma } \\
\text { istasyonları }\end{array}$ & -90 & 12 & -29.43 & 24.76 \\
\hline İş yerleri & -85 & 12 & -25.97 & 18.41 \\
\hline Konutlar & -7 & 39 & 8.95 & 9.15 \\
\hline
\end{tabular}

Çalışmada kullanılan veriler için bağımlı değiş̧ken olan hasta sayısına ait varyans, ortalamadan büyüktür. Bu nedenle aşırı yayılım olduğunu ve negatif binom regresyonu kullanımının daha uygun olduğunu söylenebilir. Negatif binom regresyon modeli için elde edilen sonuçlar Tablo 2 ve Tablo 3 de verilmiştir.

Tablo 2. Negatif binom regresyonu için uyum iyiliği ve olabilirlik oran testi sonuçları.

\begin{tabular}{cccc}
\hline & Değer & S.d. & Değer/S.d. \\
\hline Sapma & 401.414 & 358 & 1.121 \\
\hline Pearson Ki-kare & 337.364 & 358 & 0.942 \\
\hline Log Olabilirlik & -3069.980 & & \\
\hline AIC & 6155.961 & & \\
\hline Ki-Kare & 76.394 & $p=0.000$ \\
\hline
\end{tabular}

Tablo 2'ye göre sapma (değer/s.d.) 1.121 olup veri setinde aşırı yayılımın olduğu söylenir. Böylece Negatif binom regresyon modeli veri setine uygulanabilir. Uyum İyiliği için Pearson Ki-Kare (değer/s.d.) değeri 0.942 olup modelin verilere iyi uyduğu söylenebilir. Ayrıca Olabilirlik oran testi sonucuna göre Ki-Kare değeri 76.394 ve p=0.000 olup model istatistiksel olarak anlamlıdır.

Tablo 3'te Negatif binom regresyon model parametre tahminlerinden "market ve eczane" değişkeni istatistiksel olarak anlamsız olup ( $p \geq 0.05)$, diğer bağımsız değişkenler istatistiksel olarak anlamlı bulunmuştur $(p<0.05)$. Bu durumda Negatif binom regresyon modeli;

$$
\begin{aligned}
\text { hasta sayıs }= & \exp (6.856-0.025 \\
& * \text { Parakende ve rekreasyon } \\
& +\cdots+0.123 * \text { Konutlar })
\end{aligned}
$$

şeklinde ifade edilir. Elde edilen model ile yapılan tahminler ve gerçek değerlere ilişkin grafik Şekil 4'te verilmiștir.

Tablo 3. Negatif binom regresyonu için parametre tahminleri

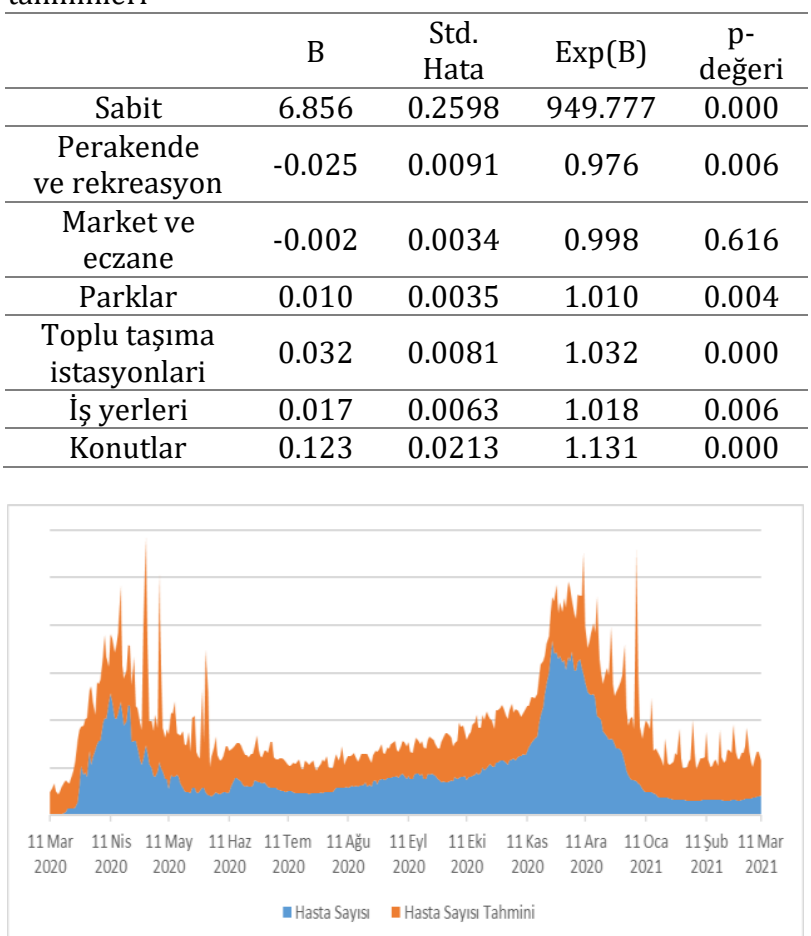

Şekil 4. Covid-19 hasta sayısı ile Regresyon model tahmini yığılmış alan grafiği

\section{Tartışma ve Sonuç}

Çalışmada Türkiye Covid-19 günlük hasta sayısı ile Türkiye Google topluluk hareketlilik türleri arasındaki ilișki negatif binom regresyon ile modellenmiștir. $\mathrm{Bu}$ doğrultuda Türkiye'de Covid-19 vakasının ilk görüldüğü günden itibaren bir yıllık zaman diliminde Türkiye Google topluluk hareketlilik türleri ile ilişkilendirme yapılmıştır.

Covid-19 salgını, Dünya üzerinde görüldüğü ilk günden itibaren tüm ülkelerin başlıca gündem maddesi olmaya devam etmektedir. $\mathrm{Bu}$ doğrultuda odaklanılan en önemli noktalardan biri de insan hareketliliğinin hastalığın bulaş durumuna ne denli etkili olduğunun ortaya konmasıdır. Çalıșmanın amacına yönelik yapılan analizler ile önemli sonuçlar elde edilmiştir. Regresyon modeli incelendiğinde perakende ve rekreasyon ile market ve eczane değişkenleri hasta sayısını negatif etkilemekte olup diğer değişkenler pozitif etkilemektedir. Hasta sayısına bağımsız değișkenlerin yüzdesel etkisi (100[Exp(B)-1]) incelendiğinde; diğer değişkenler sabitken

- Perakende ve rekreasyondaki hareketlilik bir birim arttığında hasta sayısını \%2.4 azaltmakta,

- Market ve eczanedeki hareketlilik bir birim arttığında hasta sayısını \%2 azaltmakta, 
- Parklardaki hareketlilik bir birim arttığında hasta sayısını \%1 artırmakta,

- Toplu taşıma istasyonlarındaki hareketlilik bir birim arttığında hasta sayısını \%3.2 artırmakta,

- İş yerlerindeki hareketlilik bir birim arttığında hasta sayısını \%1.8 artırmakta

- Konutlardaki hareketlilik bir birim arttığında hasta sayısını \%13.1 artırmakta,

olduğu belirlenmiştir.

Türkiye'de ilk görülen vakadan itibaren alınan önlemler gerek sokak kısitlamaları gerekse işyerlerindeki esnek çalışma gibi uygulamalar elde edilen sonuçları desteklediği görülmektedir. Genel olarak analiz sonuçlarına insan hareketliliğin artması hasta sayısının artmasına neden olduğu gibi konutlardaki hareketliliğinde yine hasta sayısına pozitif etki yaptığı bulunmuştur. Bu durum Sağlık Bakanı tarafından açıklanan mutasyon geçiren virüsün daha hızlı bulaşarak ev içi bulaşın artması durumunu desteklediğini göstermektedir [22].

Dünya genelinde mutasyonlarla birlikte etkisini devam ettiren Covid-19 salgını için yapılan çalışmada Covid-19 hasta sayısının değişimi için insan hareketliliği ile ilgili tatminkâr sonuçlar belirlenmiştir. $\mathrm{Bu}$ çalışma Google topluluk hareket raporları ile negatif binom analizi literatürüne katkı sağlayacağı düşünülmektedir. Ayrıca hasta sayısını arttırdığı belirlenen insan hareketliliği değişkenleri ile ilgili alınacak önlemler salgının kontrol altında tutulmasını ve geleceğe daha umutla bakılmasını sağlayacaktır.

Çalışmada bazı sınırlamalar mevcuttur. Öncelikle sadece Türkiye çerçevesinde konu ele alınmıştır. T.C. Sağlık Bakanlı̆̆ı tarafından açıklanan günlük hasta sayıları verileri ve Google tarafından açıklanan topluluk hareketlilik türlerinden yararlanılmıştır. Ayrıca çalışma da 11.03.2020-11.03.2021 tarihleri arasındaki veriler kullanılmıștır.

\section{Etik Beyanı}

Bu çalışmada, "Yükseköğretim Kurumları Bilimsel Araștırma ve Yayın Etiği Yönergesi" kapsamında uyulması gerekli tüm kurallara uyulduğunu, bahsi geçen yönergenin "Bilimsel Araştırma ve Yayın Etiğine Aykırı Eylemler" başliğı altında belirtilen eylemlerden hiçbirinin gerçekleștirilmediğini taahhüt ederiz.

\section{Kaynakça}

[1] World Health Organization, Coronavirus disease (COVID-19).2020.

https://www.who.int/emergencies/diseases/no vel-coronavirus-2019. (Erişim Tarihi: 15.03.2021).

[2] T.C. Sağlık Bakanlığı, COVID-19 Bilgilendirme Platformu, 2020. https://covid19.saglik.gov.tr/ (Erişim Tarihi: 15.03.2021).
[3] Banica, Arzu, A.R.I., Onder, H., 2013. Farkli veri yapilarinda kullanilabilecek regresyon yöntemleri. Anadolu Tarım Bilimleri Dergisi, 28(3), 168-174.

[4] Durmuş, A., Yeşilova, A., Çelik, E., Kara, R., 2018. Dönemeç Deltası'ndaki Kuş Populasyonları Üzerine Poisson ve Negatif Binom Regresyon Modelinin Uygulanması. Yüzüncü Yıl Üniversitesi Tarım Bilimleri Dergisi, 28(1), 78-85.

[5] Güneri, Ö.İ., Durmuş, B., 2020. Aşırı ya da Eksik Yayılım Durumunda Poisson ve Negatif Binom Regresyon Modellerinin Karşılaştırılması. Uluslararası Doğu Anadolu Fen Mühendislik ve Tasarım Dergisi, 2(1), 48-66.

[6] Yeşilova, A., Yılmaz, A., Kaki, B., 2006. Norduz erkek kuzularının bazı kesikli üreme davranış özelliklerinin analizinde doğrusal olmayan regresyon modellerin kullanılması. Yüzüncü Yıl Üniversitesi Tarım Bilimleri Dergisi, 16(2), 87-92.

[7] Kibar, F.T., 2015. Türkiye'de kamyon kazaları ile trafik ve karayolu geometrik özellikleri arasındaki ilişkinin istatistiksel ve yapay sinir ağları yöntemleri ile modellenmesi. Karadeniz Teknik Üniversitesi Fen Bilimleri Enstitüsü, Doktora Tezi, 154s, Trabzon.

[8] Saha, J., Barman, B., Chouhan, P., 2020. Lockdown for COVID-19 and its impact on community mobility in India: An analysis of the COVID-19 Community Mobility Reports, 2020. Children and youth services review, 116, 105160.

[9] Sulyok, M. and Walker, M., 2020. Community movement and COVID-19: a global study using Google's Community Mobility Reports. Epidemiology \& Infection, 148.

[10] Wang, H., Yamamoto, N., 2020. Using a partial differential equation with Google Mobility data to predict COVID-19 in Arizona. Mathematical Biosciences and Engineering, 17(5).

[11] Vokó, Z., Pitter, J.G., 2020. The effect of social distance measures on COVID-19 epidemics in Europe: an interrupted time series analysis. GeroScience, 42(4), 1075-1082.

[12] Huynh, T.L.D., 2020. Does culture matter social distancing under the COVID-19 pandemic?. Safety Science, 130, 104872.

[13] Savaris, R.F., Pumi, G., Dalzochio, J. and Kunst, R., 2021. Stay-at-home policy is a case of exception fallacy: an internet-based ecological study. Scientific reports, 11(1), 1-13.

[14] Yilmazkuday, H., 2021. Stay-at-home works to fight against COVID-19: international evidence from Google mobility data. Journal of Human Behavior in the Social Environment, 31(1-4), 210220. 
[15] Kartal, M.T., Depren, Ö., Depren, S.K., 2021. The relationship between mobility and COVID-19 pandemic: Daily evidence from an emerging country by causality analysis. Transportation Research Interdisciplinary Perspectives, 10, 100366.

[16] COVID-19 Topluluk Hareket Raporları, 2020. https://www.google.com.tr/covid19/mobility/ (Erişim Tarihi: 15.03.2021).

[17] Lauer, S.A., Grantz, K.H., Bi, Q., Jones, F.K., Zheng, Q., Meredith, H.R., Azman, A.S., Reich, N.G., Lessler, J., 2020. The incubation period of coronavirus disease 2019 (COVID-19) from publicly reported confirmed cases: estimation and application. Annals of internal medicine, 172(9), 577-582.

[18] Vikipedi, özgür ansiklopedi. COVID-19 pandemisi,

2020.

https://tr.wikipedia.org/wiki/COVID-

19 pandemisi, (Erişim Tarihi: 15.03.2021).
[19] Miaou, S.P., Hu, P.S., Wright, T., Rathi, A.K., Davis S.C., 1992. Relationship between truck accidents and highway geometric design: a Poisson regression approach. Transportation Research Record, 1376.

[20] Knuiman, M.W., Council, F.M., Reinfurt, D.W., 1993. Association of median width and highway accident rates (with discussion and closure). Transportation Research Record, 1401:70-82.

[21] Hadi, M.A., Aruldhas, J., Chow, L.F., Wattleworth, J.A., 1995. Estimating safety effects of cross-section design for various highway types using negative binomial regression. Transportation Research Record, 1500, 169.

[22] Twitter (@drfahrettinkoca),2021. https://twitter.com/drfahrettinkoca/status/134 1450917430906882, (Erişim Tarihi: 15.03.2021). 